Emir. J. Food Agric. 2009. 21 (1): 21-31

http://cfa.uaeu.ac.ae/ejfa.shtml

\title{
Assessment of intake of caffeine in random population in Riyadh and its levels in some food by HPLC
}

\author{
Nora A. Al-Faris \\ Nutrition and Food Science Department, Faculty of Home Economics, Princess Noura bint \\ Abdulrahman University
}

\begin{abstract}
This study involves 160 Saudi females of a mean age of $23 \pm 3.7$ years who regularly consumed coffee and soft drinks. The highest percentage of participants were reported to consume less than $300 \mathrm{mg}$ of caffeine daily $(42.5 \%)$ and the highest level of caffeine consumption (more than $2800 \mathrm{mg} /$ day) was calculated among $7.5 \%$ of the participants. The highest percentages of participants consuming caffeine were detected in coffee consumers followed by soft drink consumers $(93.75 \%$ and $90.63 \%$ respectively), while the least percentage was detected in tea consumers $(45.63 \%)$. The mean of consumed caffeine from coffee was the highest value $(1599 \pm 416.7)$ compared with the caffeine content in other foods. In relation to anthropometric measurements, there were no significant correlations between them and the level of caffeine consumption except weight. There was a significant correlation between the decrease in body weight and the increase in amount of caffeine consumed $(\mathrm{p}<0.05)$. On the other hand, there was no significant correlation between the hours of sleep and food consumption, and the amount of caffeine consumed $(\mathrm{p}<0.05)$. There was, however, a high correlation between the employment status of the participant and the caffeine consumption $(\mathrm{p}>0.05)$.
\end{abstract}

Keywords: Caffeine, Xanthine alkaloid, coffee, soda, Saudi Arabia, anthropometric measures.
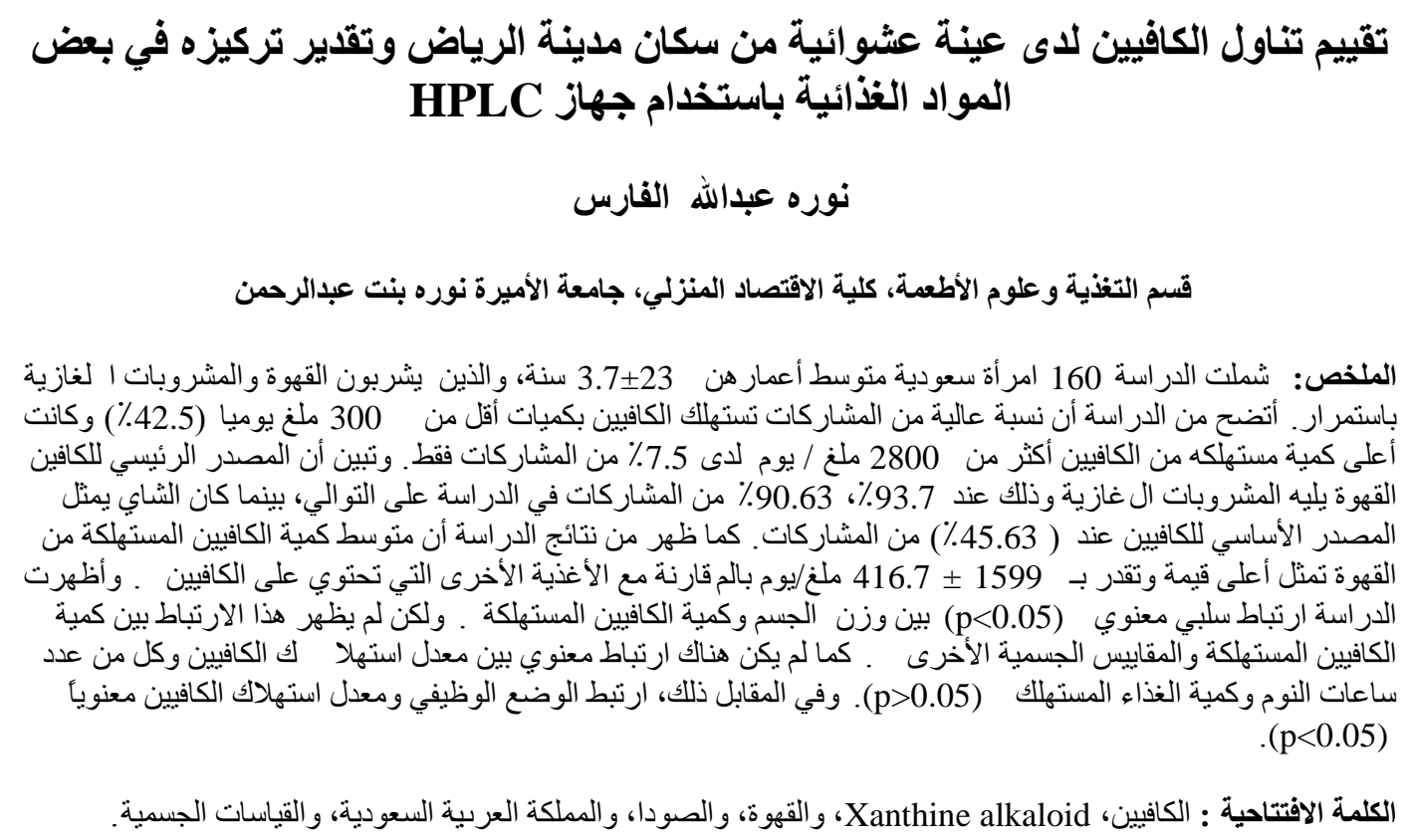

\section{Introduction}

Humans have consumed caffeine since the Stone Age (Escohotado, 1999). Caffeine is a bitter white crystalline xanthine alkaloid that acts as a psychoactive stimulant drug and a mild diuretic (speeds up urine production) in humans and other animals (Armstrong, 2002). Caffeine was discovered by a German chemist, Friedrich Ferdinand Runge, in 1819. The disparity in experience and effects between the various 
natural caffeine sources could be due to the fact that plant sources of caffeine also contain widely varying mixtures of other xanthine alkaloids, including the cardiac stimulants theophylline and theobromine and other substances such as polyphenols which can form insoluble complexes with caffeine (Balentine et al., 1998).

Caffeine is found in varying quantities in the beans, leaves, and fruit of over 60 plants, where it acts as a natural pesticide that paralyzes and kills certain insects feeding on the plants (Nathanson, 1984); and as an inhibitor of seed germination of other nearby coffee seedlings (Baumann and Gabriel, 1984), thus giving it a better chance of survival. It is most commonly consumed by humans in the form of infusions extracted from the beans of the coffee plant and the leaves of the tea bush, as well as from various foods and drinks containing products derived from kola nut or cacao. Other sources include yerba mate, guarana berries, and the Yaupon Holly (Matissek, 1997).

The world's primary source of caffeine is the coffee bean (the seed of the coffee plant). Caffeine content in coffee varies widely depending on the type of coffee bean and on the method of preparation (Stavric, 1988). Beans within a given bush can show variations in caffeine concentration. In general, one serving of coffee ranges from 40 milligrams, for a single shot (30 milliliters) of Arabica variety espresso, to about 100 milligrams for a cup (120 milliliters) of drip coffee. Generally, dark-roast coffee has less caffeine than lighter roasts because the roasting process reduces the bean's caffeine content (Lecos, 1984 and Bruce, 1986). Arabica coffee normally contains less caffeine than the robusta variety (Stavric, 1988). Coffee also contains trace amounts of theophylline, but no theobromine.

Tea is another common source of caffeine. Although tea contains more caffeine than coffee, a typical serving contains much less, as tea is normally brewed much weaker. Besides the strength of the brew, growing conditions, processing techniques and other variables also affect caffeine content. Certain types of tea may contain more caffeine than others. In general, tea contains small amounts of theobromine and slightly higher levels of theophylline than coffee. Preparation and many other factors have a significant impact on tea, and color is a very poor indicator of caffeine content. Teas like the pale Japanese green tea gyokuro, for example, contain far more caffeine than much darker teas like lapsang souchong, which has very little (Food Research International, 1996).

Caffeine is also a common ingredient of soft drinks such as cola, originally prepared from kola nuts. Soft drinks typically contain about 10 to 50 milligrams of caffeine per serving (Haskell et al., 2007). Chocolate derived from cocoa contains a small amount of caffeine. In addition to its caffeine content, the weak stimulant effect of chocolate may also be due to a combination of theobromine and theophylline (Smit et al., 2004). Chocolate contains too little of these compounds per reasonable serving to create an effect in humans. A typical 28 gram serving of a milk chocolate bar has approximately as much caffeine as a cup of decaffeinated coffee (Smith, 2002).

Caffeine is also packed in the form of tablets, with the claim that using caffeine of pharmaceutical quality improves mental alertness and is used by students during the exams period. It is also used by people who work or drive for long hours (Ivan, 2008).

Caffeine is a central nervous system and metabolic stimulant (Nehlig et al., 1992) and is used both recreationally and medically to reduce physical fatigue and restore mental alertness when unusual weakness or drowsiness occurs. Caffeine stimulates the central nervous system first at higher levels, resulting in increased alertness and wakefulness, faster and clearer flow of thought, increased focus, and better general body coordination; and later at the spinal cord level at higher doses (Bolton, 1981). Caffeine is completely absorbed by the stomach and small intestine within 45 
minutes of ingestion. After ingestion it is distributed throughout all tissues in the body and then eliminated by first-order kinetics (Newton et al., 1981). Caffeine can also be ingested rectally, evidenced by the formulation of suppositories of ergotamine tartrate and caffeine for the relief of migraine (Graham, 1954); and chlorobutanol and caffeine for the treatment of hyperemesis (Brødbaek and Damkier, 2007).

The half-life of caffeine (the time required for the body to eliminate one-half of the total amount of caffeine consumed at a given time) varies widely among individuals and depends on factors such as age, liver function, pregnancy, some concurrent medications, and the level of enzymes in the liver needed for caffeine metabolism. In healthy adults, caffeine's half-life is approximately 3 to 4 hours. In women taking oral contraceptives this is increased to 5 to 10 hours (Meyer et al., 1991), and in pregnant women the half-life is roughly 9 to 11 hours (Ortweiler et al., 1985). Caffeine can accumulate in individuals with severe liver disease, increasing its half-life up to 96 hours (Bolton, 1981). In infants and young children, the half-life may be longer than in adults, while the half-life in a newborn baby may be as long as 30 hours. Other factors such as smoking can shorten caffeine's halflife (Springhouse, 2005).

Caffeine is metabolized in the liver by the cytochrome $\mathrm{P}_{450}$ oxidase enzyme system into three metabolic dimethylxanthines, which each have their own effects on the body: Paraxanthine ( $84 \%$ ), has the effect of increasing lipolysis, leading to elevated glycerol and free fatty acid levels in the blood plasma, Theobromine (12\%) dilates blood vessels and increases urine volume and Theophylline (4\%) relaxes smooth muscles of the bronchi, and is used to treat asthma. Each of these metabolites is further metabolized and then excreted in the urine (Fisone et al., 2004).

Taking into account all of these various factors, the objectives of this study are to assess the intake of caffeine in a random sample of female population in Riyadh, determine caffeine levels in some foods by HPLC, propose guidelines that may aid practitioners in advising their population, and provide recommendations for future research.

\section{Materials and Methods}

\section{Data collection}

The study was conducted on healthy women who regularly visited the Central Riyadh hospital and Al-yamamah hospital, Riyadh, Kingdom of Saudi Arabia. The data was collected from a sample of one hundred sixty Saudi people, out of which the average age was determined to be $23 \pm 4$ through a self-administered questionnaire. In addition to the information about their socioeconomic characteristics, the participants were asked to indicate the quantity of their daily consumption of caffeine containing foods and drinks.

Questions concerning demographics, medical history, lifestyle habits (e.g. smoking, illicit drug use, caffeine), environmental and occupation exposures, and psychosocial stresses, were included in the questionnaire.

\section{Detection of caffeine consumption}

To measure caffeine consumption, a 7 day recalls method was used, in which the participants recorded both the type and amount of all beverages consumed during the preceding 7 days. Female participants were questioned about the type (i.e. caffeinated or decaffeinated coffee, tea, soft drinks, cocoa drinks, milk chocolate, and dark chocolate) and amount (i.e. number of cups, glasses, or ounces per day and/or week) of caffeine consumed during the various time periods. Also, the questionnaire included other types of food. Caffeine intake was converted to exact amounts in $\mathrm{mg}$, based on estimates reported in several previous studies (Wilcox et al., 1988; Clausson and Granath, 2002 and Derbyshire and Abdula, 2008) and various 
nutrition tables. For each time period, the total amount of caffeine was calculated by adding the amounts consumed through all food products containing caffeine.

\section{Determination of caffeine}

58 samples of foods and beverages containing caffeine (as shown table 1a and 1b) were analyzed by using highperformance liquid chromatography (SHIMADZU HPLC) with a UV Detector $(\lambda 273 \mathrm{~nm})$. This method provides separation by utilizing a non-polar stationary phase chemically bonded to an inert support in a column through which a polar mobile phase passes. The mobile phase consisted of $60 \%$ ammonium acetate $(005 \mathrm{M}), 40 \%$ methanol ((HPLC GRADE) COLUMN: RESTICpinnacle II $\mathrm{C} 18$ 5U $(150 \mathrm{X} 4.6 \mathrm{~mm}$ cat=9214565) $\quad\left(\right.$ AOAC, $16^{\text {th }}$ ed., 1990) $)$. Compounds (including caffeine) in the study samples which have different polarities, are distributed between the stationary and mobile phase differently, and are thus eluted from the column at different times. As caffeine exhibits ultraviolet absorption, a variable wavelength detector was used to measure elution from the column.

To prepare the samples from carbonated beverages, they were decarbonated by sonicating for 5 to 10 minutes and then diluted with ammonium acetate buffer. For coffee and tea samples, $1 \mathrm{~g}$ of each was weighed into a $100 \mathrm{ml}$ volumetric flask, dissolved by adding boiling water, cooled and diluted to the mark. The sample was filtered through the sample clarification kit prior to injection.

The HPLC was set up for analysis and the buffer was set up on channel A and the methanol on channel $\mathrm{B}$. The solvents were degassed under vacuum for 30 minutes before use. The variable wavelength detector was turned on 15 minutes before the first injection. After equilibrating the column with the mobile phase for 30 minutes, $10 \mathrm{ul}$ of the standard mixture was injected. As caffeine has an approximate retention time of 5.4 minutes and with the instrument set to the relative percent mode, the area of caffeine peak was calculated and then used to quantitate its component in the sample.

\section{Statistical analyses}

Results with high measures of associations $(\mathrm{OR}>2.0)$ or overall $P$-values $\leq 0.05$ were presented with corresponding 95\% CI. All analyses were performed using STATA software (Stata Corp., College Station, TX, USA).

\section{Results}

Tables $1 \mathrm{a}$ and $1 \mathrm{~b}$ show the results of measurement of caffeine contents in foods and beverages using HPLC. Among the coffees, it can be seen that Turkish coffee contains the highest amount of caffeine (2905.5 mg) followed by Starbucks coffee $(1516.7 \mathrm{mg})$, while the coffee with chocolate (Rabai) contains the least amount of caffeine $(129.3 \mathrm{mg})$. Among chocolate beverages, chocolate milk ((Al-Othman Agri. Prod \& Proc. Co.) (NADA)) contains the highest amount of caffeine $(79.1 \mathrm{mg}$ ) followed by Chocolate milk (Al-Marai) (67.6 mg) and chocolate milk (Korenta) (22.4 mg). Among chocolates, M\&Ms is the ones contain the highest amount of caffeine $(466.5 \mathrm{mg}$ ) followed by Maltesers (288.6 $\mathrm{mg}$ ) and the least amount was found in Tola Nest chocolate $(33 \mathrm{mg})$. The soft drink with the highest amount of caffeine was Power Play drink $(331 \mathrm{mg})$ followed by BoomBoom drink (306.7 mg), while the drink which had the least amount of caffeine is Pepsi-Cola (Al-Jomaih) (90 mg). Among the teas, green tea (leaf) contains the highest amount of caffeine $(308 \mathrm{mg}$ ) followed by red tea (leaf) $(281 \mathrm{mg})$, while green tea (Lipton) had the least amount of caffeine (49.3 mg).

Table 2 shows the percentage of participants consuming different amounts of caffeine as recorded through a 7-day recall (mg/day). The highest percentage of participants was reported to consume less than $300 \mathrm{mg}$ of caffeine daily $(42.5 \%)$ 
Emir. J. Food Agric. 2009. 21 (1): 21-31

http://cfa.uaeu.ac.ae/ejfa.shtml

followed by $30 \%$ of participants consuming between 300 and $800 \mathrm{mg}$ of caffeine daily. The highest level of caffeine consumption (more than $2800 \mathrm{mg} /$ day) was found in $7.5 \%$ of participants. There was a significant negative correlation between the number of participants consuming caffeine and the amount of caffeine consumed; with one exception that was recorded at the highest level of caffeine consumption $(7.5 \%$ consumed more than $2800 \mathrm{mg}$ daily).

Table 1a. Caffeine content in 23 foods and beverages measured by HPLC.

\begin{tabular}{lcc}
\hline \multicolumn{1}{c}{ Food and Beverage } & \multicolumn{2}{c}{ Caffeine (mg/L) } \\
\hline Coffee & Mean & Std. Error \\
\hline Arabic coffee 1(Boiling time is 10 min) & 368.5 & 19.5 \\
Arabic coffee 2 (Boiling time is 20 min) & 426.4 & 28.4 \\
Arabic coffee 3(Boiling time is 30 min) & 595.2 & 6.6 \\
Dr. Café coffee & 1272 & 106 \\
Cafa coffee & 943.5 & 5.5 \\
Turkish coffee & 2905.5 & 2.5 \\
Coffee time coffee & 958.8 & 1.6 \\
Star-Bucks coffee & 1516.7 & 13.6 \\
Coffee with chocolate (Rabie) & 129.3 & 3.3 \\
Nescafe coffee (Nestle) & 824.8 & 11.8 \\
Soft Drinks & & \\
Pepsi-Cola (Al-Jomaih) & 90 & 1 \\
Mountain dew (Coco-Cola) & 84.9 & 15.1 \\
Fanta Citrus (Coco-Cola) & 137 & 2 \\
Spicy Cola (Abuljadayel Beverages Inc) & 101.7 & 3.3 \\
Be Cola (Mahmood Saeed Beverage Industry ) & 114.7 & 4.8 \\
Gel Strong (Abuljadayel Beverages Inc) & 157.6 & 2.2 \\
Power play (Coco-Cola) & 331 & 1 \\
Bison (Abuljadayel Beverages Inc) & 258 & 3 \\
Boom-Boom (Mahmood Saeed Beverage Industry) & 306.7 & 3.7 \\
Tea & & \\
Green Tea (Leaf) & 308 & 2 \\
Red Tea (Leaf) & 281 & 3 \\
Green Tea (Lipton) & 49.3 & 1.3 \\
Red Tea (Lipton) & 247.5 & 0.6 \\
\hline Caffeine content was measured in the different foods by HPLC as described in Materials and \\
Methods. Results are shown as mean \pm SEM and are the average of 2 determinations. \\
\end{tabular}


Table 1b. Caffeine content in 35 foods and beverages measured by HPLC.

\begin{tabular}{|c|c|c|}
\hline \multirow[t]{2}{*}{ Food and Beverage } & \multicolumn{2}{|c|}{ Caffeine (mg/L) } \\
\hline & Mean & Std. Error \\
\hline \multicolumn{3}{|l|}{ Chocolate Beverages } \\
\hline Chocolate milk (Al-Othman Agri. Prod \& Proc. Co.) (NADA) & 79.1 & 4.1 \\
\hline Chocolate milk (K.D.A.) & 53.1 & 6.1 \\
\hline Chocolate milk (Saudi Dairy \& Foodstuff Co.) (SADAFCO) & 26.2 & 1.2 \\
\hline Chocolate milk (Rabie) & 39.9 & 0.1 \\
\hline Chocolate milk (Al-Marai) & 67.6 & 1.5 \\
\hline Chocolate milk (Al-hana) & 39.9 & 1.9 \\
\hline Chocolate milk (GALAXY) & 58 & 0.1 \\
\hline Chocolate milk-chic (Saudi Dairy\& Foodstuff Co.) (SADAFKO) & 35.7 & 2.1 \\
\hline Chocolate milk (Korenta) & 22.4 & 0.4 \\
\hline Chocolate milk (Almazrah Marketing Establishement) & 25.6 & 0.6 \\
\hline Chocolate milk (The National Development Co.) (NADEC) & 27 & 3 \\
\hline Chocolate milk (Strong cow) & 52 & 2 \\
\hline Chocolate milk (Jamjoom) & 45.4 & 5.2 \\
\hline Chocolate milk (Najdiyah) & 33.4 & 0.4 \\
\hline Chocolate milk (Al Safi Danone) & 3.8 & 0.9 \\
\hline Saudi-milk with chocolate (SADAFKO) & 53.8 & 4.4 \\
\hline Carmel chocolate drink (Rabie) & 66 & 2 \\
\hline \multicolumn{3}{|l|}{ Chocolate } \\
\hline Chocolate Galaxy (Mars-Galaxy Chocolate Company) & 250.8 & 2.6 \\
\hline Kinder chocolate (Ferrero S.P.A.) & 122.6 & 3.6 \\
\hline French chocolate (Alzwak) & 243 & 5 \\
\hline Swiss chocolate (Alzwak) & 143.8 & 4.1 \\
\hline Syrian chocolate & 233.9 & 2.9 \\
\hline Kit-Kat (Nestle) & 147.1 & 6.1 \\
\hline M\&Ms (Master-foods) & 466.5 & 4.5 \\
\hline Galaxy Cake (Mars-G.C.C) & 122.8 & 2.5 \\
\hline Belgium Cake & 59.6 & 6.6 \\
\hline Maltesers (Mars-G.C.C) & 288.6 & 1.6 \\
\hline Danit (Al Safi Danone) & 68 & 3 \\
\hline Snickers (Master-foods) & 105.5 & 1.9 \\
\hline Lego & 235.4 & 4.4 \\
\hline Nestle tempt (Nestle) & 281.7 & 2.5 \\
\hline Tola Nest (Nestle) & 33 & 1 \\
\hline Bawenty (Master-foods) & 64.2 & 1.3 \\
\hline BonSweet Chocolate Custard (Al-Marai) & 61.3 & 2.3 \\
\hline BonSweet Chocolate with Cream (Al-Marai) & 252.3 & 2.5 \\
\hline
\end{tabular}

Caffeine content was measured in the different foods by HPLC as described in Materials and Methods. Results are shown as mean \pm SEM and are the average of 2 determinations. 
Emir. J. Food Agric. 2009. 21 (1): 21-31

http://cfa.uaeu.ac.ae/ejfa.shtml

Table 2. Percentage of participants consuming different amount of caffeine recorded by 7-day recalls (mg/day).

\begin{tabular}{cc}
\hline $\begin{array}{c}\text { Caffeine consumption } \\
(\mathbf{m g} / \mathbf{d a y})\end{array}$ & $\begin{array}{c}\text { Number of participants } \\
(\mathbf{\%})\end{array}$ \\
\hline$<300$ & $68(42.5)$ \\
$300-800$ & $48(30)$ \\
$801-1300$ & $16(10)$ \\
$1301-1800$ & $8(5)$ \\
$1801-2300$ & $1(0.63)$ \\
$2301-2500$ & $4(2.5)$ \\
$2501-2800$ & $3(1.87)$ \\
$>2800$ & $12(7.5)$ \\
Total & $160(100)$ \\
\hline
\end{tabular}

Table 3 shows the mean of caffeine consumption in coffee, chocolate beverages, chocolate, soft drinks and tea, and the percentage of participants who consumed caffeine from each of these food and beverage sources. The highest percentage of participants that consumed caffeine were coffee consumers followed by soft drink consumers $\quad(93.75 \%$ and $90.63 \%$ respectively), while the lowest percentage was detected in tea consumers $(45.63 \%)$. The mean of consumed caffeine from coffee was the highest value $(1599 \pm 416.7)$ compared to any other caffeine containing source.

Table 3. Means of caffeine consumption and percentages of participants.

\begin{tabular}{lcc}
\hline Food and Beverage & $\begin{array}{c}\text { Number of participants } \\
(\boldsymbol{\%})\end{array}$ & $\begin{array}{c}\text { Caffeine consumption } \\
(\mathbf{M g} / \mathbf{d})\end{array}$ \\
\hline Coffee & $150(93.8)$ & $1599 \pm 416.7$ \\
Chocolate Beverages & $97(60.6)$ & $67.9 \pm 3.7$ \\
Chocolate & $108(67.5)$ & $472.5 \pm 170.7$ \\
Soft drink & $145(90.6)$ & $679.7 \pm 211.7$ \\
Tea & $73(45.6)$ & $196.8 \pm 16.4$ \\
\hline
\end{tabular}

Table 4 shows the correlation between the amount of caffeine consumption (mg/day) and general characteristics of participants, and the $95 \%$ confidence interval of caffeine consumption for different groups of study. There was no correlation between the mean age $(23 \pm 4)$ of the studied population and the amount of caffeine consumed ( $\mathrm{p}>0.05)$. With regard to anthropometric measurements (height, weight, chest circumference, waist circumference, and hip circumference), there was no correlation between them and the level of caffeine consumption except for weight. On the other hand, there was a significant negative correlation between the decrease in body weight and the increase in the amount of caffeine consumed $(\mathrm{p}<0.05)$. There was also a significant negative correlation between the employment status of the participants and the amount of caffeine consumed ( $\mathrm{p}<$ 0.05 ). On the other hand, there was no correlation between the hours of sleep and the amount of caffeine consumed $(p<0.05)$. 
Table 4. Correlations between the amount of caffeine consumption (mg/day) and general characteristics of participants.

\begin{tabular}{|c|c|c|c|c|c|c|c|c|c|c|}
\hline & \multicolumn{9}{|c|}{ Amount of caffeine (mg/day) } & \multirow[b]{2}{*}{$P$} \\
\hline & $\begin{array}{l}<300 \\
\mathrm{~N}=68\end{array}$ & $\begin{array}{c}300-<800 \\
N=48\end{array}$ & $\begin{array}{c}800-<1300 \\
N=16\end{array}$ & $\begin{array}{c}1300-<1800 \\
N=8\end{array}$ & $\begin{array}{c}1800-<2300 \\
N=1\end{array}$ & $\begin{array}{c}2300-<2500 \\
N=4\end{array}$ & $\begin{array}{c}2500-<2800 \\
N=3\end{array}$ & $\begin{array}{c}>2800 \\
\mathrm{~N}=12\end{array}$ & $\begin{array}{c}\text { Total } \\
\text { N=160 }\end{array}$ & \\
\hline Age (years) & $22.2 \pm 3.3$ & $23.9 \pm 4.1$ & $22.8 \pm 3.5$ & $23 \pm 3.5$ & 21 & $25 \pm 3.6$ & $24 \pm 2$ & $23.3 \pm 3.8$ & $23 \pm 3.7$ & $\mathrm{NS}^{1}$ \\
\hline Length (cm) & $159 \pm 5.6$ & $159 \pm 8.1$ & $163 \pm 8.6$ & $166 \pm 12$ & 163 & $161 \pm 14.4$ & $159 \pm 7.8$ & $163 \pm 6$ & $160 \pm 7.6$ & NS \\
\hline Weight (Kg) & $65 \pm 9.9$ & $62 \pm 11.6$ & $64 \pm 7.7$ & $61 \pm 22.8$ & 62 & $51 \pm 5.3$ & $59 \pm 14.4$ & $53 \pm 9.6$ & $60 \pm 12$ & $<0.05$ \\
\hline Chest circumference (cm) & $86 \pm 9.3$ & $90 \pm 17.6$ & $83 \pm 10.4$ & $90 \pm 10.1$ & 91 & $86 \pm 9.5$ & $88 \pm 13.1$ & $88 \pm 10.5$ & $87 \pm 12.6$ & NS \\
\hline Waist circumference (cm) & $76 \pm 7.7$ & $79 \pm 13$ & $74 \pm 9.9$ & $76 \pm 9.7$ & 85 & $78 \pm 6.7$ & $80 \pm 6.1$ & $77 \pm 9.3$ & $77 \pm 9.9$ & NS \\
\hline Hip circumference (cm) & $100 \pm 11$ & $99 \pm 18.5$ & $91 \pm 23.2$ & $106 \pm 11$ & 108 & $102 \pm 9$ & $108 \pm 11.2$ & $101 \pm 9.8$ & $99 \pm 15.3$ & NS \\
\hline Hours of sleep & $6.2 \pm 1.6$ & $6.6 \pm 2.3$ & $6.7 \pm 1.9$ & $7.3 \pm 2.3$ & 4 & $4.8 \pm 3.1$ & $5.7 \pm 3.8$ & $7.6 \pm 2.3$ & $6.4 \pm 2.1$ & NS \\
\hline Natural feeding (month) & $8.1 \pm 8.1$ & $10.3 \pm 4.8$ & $8.8 \pm 4.7$ & $12.8 \pm 2.9$ & $7.3 \pm 8.2$ & $5.9 \pm 8.6$ & $7.4 \pm 5.2$ & $6.3 \pm 3.9$ & $8.5 \pm 8.2$ & NS \\
\hline $\begin{array}{l}\text { Employment: } \\
\text { Yes } \\
\text { No }\end{array}$ & $\begin{array}{l}47 \\
21\end{array}$ & $\begin{array}{l}36 \\
12\end{array}$ & $\begin{array}{c}14 \\
2\end{array}$ & $\begin{array}{l}7 \\
1\end{array}$ & $\begin{array}{l}1 \\
0\end{array}$ & $\begin{array}{l}4 \\
0\end{array}$ & $\begin{array}{l}2 \\
1\end{array}$ & $\begin{array}{c}11 \\
1\end{array}$ & $\begin{array}{c}122 \\
38\end{array}$ & $<0.05$ \\
\hline
\end{tabular}




\section{Discussion}

Foods and beverages containing caffeine have been consumed for thousands of years, yet questions persist about their potential effects on women's health. According to leading medical and scientific experts, caffeine in moderation usually can be safely consumed by healthy individuals (American Academy of Pediatrics' Committee on Drugs, 2001).

Until now, there have been limited local studies on the subject of amount of caffeine consumption and its effect on health. In this study, caffeine consumption from food and beverage sources was calculated based on a 7-day recall which is a limited resource due to the fact that participants may not record all the food and/or beverages that they consumed in the 7 days (Sanjur, 1982 and Al-Shoshan, 2007). Also, some participants recorded only coffee or tea and did not include chocolates, soft drinks and other beverages containing caffeine.

In this study, the most commonly consumed caffeine containing food was coffee (particularly the three types of Arabic coffee, 93.75\%), followed by soft drinks (particularly Power Play drink, 90.63\%). This observation was in agreement with the study in North America, where $90 \%$ of adults consume caffeine daily (Lovett and Richard, 2005). The U.S. Food and Drug Administration lists caffeine as a "Multiple Purpose Generally Recognized as Safe Food Substance" (U.S. Code of Federal Regulations 462, 2007).

Measurements of caffeine content in foods and beverages by using HPLC revealed that the Turkish coffee contains the highest amount of caffeine, followed by Starbucks coffee and Dr. Café coffee. In the soft drinks category, Power Play drink contains the highest amount of caffeine followed by Boom-Boom drink, while Pepsi Cola (Al-Jomaih), contains the least amount. Among the teas, green tea (leaf) contains the highest amount of caffeine followed by red tea (leaf), while green tea (Lipton) contains the least amount of caffeine. The Arabic coffee (three types) which is the preferred drink in Saudi Arabia, contains amounts of caffeine which is within the safe range (less than 300 $\mathrm{mg}$ /day, roughly equivalent to 5 cups of coffee). The three types of Arabic coffee used in this study vary in the amount of caffeine they contain. The caffeine content depends on the duration of boiling time, and the highest amount in this case, is present in the coffee with longest boiling time. Studying the relationship between the amount of caffeine consumption (mg/day) and general characteristics of participants revealed that, there is a correlation between high caffeine consumption and low body weight. This is in agreement with other studies that confirm that caffeine consumption up to certain level is beneficial to humans, while it would be harmful if it exceeds that level (Institute of Food Technologists, 1987 and Food research International, 1996).

The vast bulk of scientific and epidemiological evidence points to the conclusion that, regular consumption of coffee and caffeine containing beverages within limits is not associated with disease (Rubin and Rita, 2008) or with changes in sleeping pattern as observed in this study. There was however, a high correlation between the employment status of the participant and the amount of caffeine consumed (Nawrot et al., 2003).

In summary, this study provides new insights into caffeine consumption habits in a random sample of female population in Riyadh. These data and the assessment of caffeine concentrations in several foods by HPLC, are useful for health professionals in advising patients about safe caffeine consumption.

\section{References}

Al-Shoshan, A. A. 2007. Predictors of Caffeine Consumption among Young Women, Pakistan Journal of Nutrition 6(6):597-602. 
American Academy of Pediatrics' Committee on Drugs. 2001. The transfer of drugs and other chemicals into human milk. Pediatrics. 108(3):776-789.

AOAC, $16^{\text {th }}$ edition. 1990. SHIMADZU HPLC APPARATUS.

Armstrong, L. E. 2002. Caffeine, body fluid-electrolyte balance, and exercise performance. International Journal of Sport Nutrition and Exercise Metabolism. 12:189-206.

Balentine, D. A., M. E. Harbowy and H. N. Graham. 1998. Tea: the Plant and its Manufacture; Chemistry and Consumption of the Beverage. European Food Research and Technology 17(78):234-8.

Baumann, T. W. and H. Gabriel. 1984. Metabolism and excretion of caffeine during germination of Coffea arabica L. Plant and Cell Physiology, Oxford Journals 25(8):1431-6.

Bolton, D. E. 1981. Caffeine: Psychological Effects, Use and Abuse. Orthomolecular Psychiatry 10(3):202-211.

Brødbaek, H. B. and P. Damkier. 2007. The treatment of hyperemesis gravidarum with chlorobutanol-caffeine rectal suppositories in Denmark: practice and evidence (in Danish). Ugeskr. Laeg. 169 (22):2122-3.

Bruce, M. S. 1986. Caffeine contents. British Journal of Clinical Pharmacology 22:81-87.

Clausson, B. and F. Granath. 2002. Effect of caffeine exposure during pregnancy on birthweight and gestational age. American Journal of Epidemiology 155:429-436.

Derbyshire, E. and S. Abdula. 2008. Habitual caffeine intake in women of childbearing age. J. of Hum. Nut. and DM. Vol. 21(6):527-529.

Escohotado, A. 1999. A Brief History of Drugs: From the Stone Age to the Stoned Age. Park Street Press. pp. 8263.

Fisone, G., A. Borgkvist and A. Usiello. 2004. Caffeine as a psychomotor stimulant: mechanism of action. Cell Mol. Life Sci. 61(7-8):857-72.

Food research International. 1996. Caffeine in tea vs. steeping time. The content of caffeine in various teas and styles of brew were compared. 29:325-330.

Graham, J. R. 1954. Rectal use of ergotamine tartrate and caffeine alkaloid for the relief of migraine. N. Engl. J. Med. 250(22):936-8.

Haskell, C. F., D. Kennedy, K. A. Wesnes, A. L. Milne and A. B. Scholey. 2007. A double-blind, placebo-controlled, multidose evaluation of the acute behavioural effects of guarana in humans. J. Psychopharmacol 21(1):65-70.

Institute of Food Technologists. 1987. Evaluation of Caffeine Safety, a scientific status summary by Expert Panel on Food Safety and Nutrition. Food Technology, Institute of Food Technologists, Chicago 41(6):105-113.

Ivan, S. 2008. Altasterol Caffeine Pro + and Mental Alertness. J. Hist. Behav. Sci. 27(1):42-55.

Lecos, C. 1984. The latest caffeine scorecard. FDA Consumer, March.

Lovett, A. B. and H. Y. Richard. 2005. Coffee: The demon drink. New Scientist 2518(10)1096-2496.

Matissek, R. 1997. Evaluation of xanthine derivatives in chocolate: nutritional and chemical aspects. European Food 
Research and Technology 205(3):17584.

Meyer, F. P., E. Canzler, H. Giers, and H. Walther. 1991. Time course of inhibition of caffeine elimination in response to the oral depot contraceptive agent Deposiston. Hormonal contraceptives and caffeine elimination. Zentralbl Gynakol 113(6):297-302.

Nathanson, J. A. 1984. Caffeine and related methylxanthines: possible naturally occurring pesticides. Science 226(4671):184-7.

Nawrot, P., S. Jordan, J. Eastwood, J. Rotstein, A. Hugenholtz and M. Feeley. 2003. Effects of Caffeine on Human Health. Food Additives and Contaminants 20:1-30.

Nehlig, A., J. L. Daval, and G. Debry. 1992. Caffeine and the central nervous system: Mechanisms of action, biochemical, metabolic, and psychostimulant effects. Brain Res. Rev. 17(2):139-70.

Newton, R., L. J. Broughton, M. J. Lind, P. J. Morrison, H. J. Rogers, and I. D. Bradbrook. 1981. Plasma and salivary pharmacokinetics of caffeine in man. European Journal of Clinical Pharmacology 21(1):45-52.

Ortweiler, W., H. U. Simon, F. K. Splinter, G. Peiker, C. Siegert, and A. Traeger. 1985. Determination of caffeine and metamizole elimination in pregnancy and after delivery as an in vivo method for characterization of various cytochrome p-450 dependent biotransformation reactions. Biomed Biochim Acta. 44(7-8):1189-99.

Rubin, D. W. and S. E. Rita. 2008. New studies, different outcomes on caffeine, pregnancy. USA TODAY.

Sanjur, D. 1982. Social and cultural perspectives in nutrition. Englewood Cliffs, NJ:Prentice-Hall pp.172-175.

Smith, A. 2002. Effects of Caffeine on Human Behavior. Food and Chemical Toxicology 40:1243-1255.

Smit, H. J., E. A. Gaffan, and P. J. Rogers. 2004. Methylxanthines are the psycho-pharmacologically active constituents of chocolate. Psychopharmacology 176(3-4):412-9.

Springhouse. 2005. Physician's Drug Handbook, 11th edition. Lippincott Williams \& Wilkins. ISBN 1-58255396-3.

Stavric, B. 1988. Variability in caffeine consumption from coffee and tea: possible significance for epidemiological studies. Fd. Chem. Toxic 26(2):111-118.

U.S. Code of Federal Regulations 462. 2007. 21 CFR 182.1180. U.S. Office of the Federal Register (2003-04-01). Retrieved on 2007-02-16.

Wilcox, A., C. Weinberg and D. Baird. 1988. Caffeinated beverages and decreased fertility. The Lancet 2:1453-1455. 